\title{
Estudo da incorporação de pó de concha de marisco em massa de porcelanato
}

\section{(Study of the incorporation of mollusk shell powder in mass of porcelain tile)}

\author{
E. B. G.A.Fulgêncio ${ }^{1}$,F. K. de Medeiros ${ }^{1}$, J.M.Cartaxo ${ }^{2}$, R. P. S. Dutra ${ }^{1}$, D.A. Macedo ${ }^{1}$, L.F.A.Campos ${ }^{1 *}$ \\ ${ }^{1}$ Universidade Federal da Paraíba, Programa de Pós-Graduação em Ciência e Engenharia de Materiais, \\ 58051-900, João Pessoa, Brasil \\ ${ }^{2}$ Universidade Federal de Campina Grande, Unidade Acadêmica de Engenharia de Materiais, \\ Campina Grande, Brasil
}

\begin{abstract}
Resumo
A pesca de mariscos é uma das atividades comerciais mais importantes da comunidade pesqueira do município de Cabedelo (Paraíba, Brasil). O processo de beneficiamento, após a extração do molusco, gera elevada quantidade de conchas, cujo descarte, em volume considerável, provoca assoreamento de áreas extensas e consequente desequilíbrio ambiental. Na busca do aproveitamento desses resíduos (conchas de mariscos) e visando a redução dos problemas ambientais causados, esse trabalho teve como objetivo o estudo da incorporação de pó de conchas de mariscos em massa de porcelanato. Composições cerâmicas foram formuladas a partir de uma massa de porcelanato industrial e pó de concha de marisco ou $\mathrm{CaCO}_{3}$ comercial variando entre 0 e $7 \%$ em massa. Corpos de prova preparados por prensagem uniaxial tiveram suas propriedades tecnológicas avaliadas em função da temperatura de sinterização. Os resultados indicaram que o uso de até $7 \%$ em massa de pó de concha mantém as propriedades tecnológicas dentro dos padrões exigidos pela ABNT (Brasil) para a classificação como cerâmicas de revestimento do grupo BIa.
\end{abstract}

Palavras-chave: conchas de marisco, cerâmica branca, reutilização, desenvolvimento sustentável.

\begin{abstract}
The fishing of shellfish is one of the most important commercial activities of the fishing community of the municipality of Cabedelo (Paraiba, Brazil). The step of processing, after the extraction of the mollusk, generates a large amount of shells, whose discharge, in considerable volume, causes silting of large areas and consequent environmental imbalance. In the search for the use of these residues (mollusk shells) and aiming at reducing the environmental problems caused, this work had the aim of studying the incorporation of mollusk shell powder in the mass of porcelain tile. Ceramic compositions were formulated from an industrial standard mass and mollusk shell powder or commercial $\mathrm{CaCO}_{3}$ ranging from 0 to $7 \%$ by weight. Samples prepared by uniaxial pressing had their technological properties evaluated as a function of the sintering temperature. The results indicated that the use of up to 7 wt\% of the mollusk shell powder maintains the technological properties within the standards required by the ABNT (Brazil) for classification as BIa type porcelain tiles.
\end{abstract}

Keywords: mollusk shells, white ceramic, reuse, sustainable development.

\section{INTRODUÇÃO}

O desafio na produção do porcelanato inicia-se na seleção das matérias-primas que compõem a massa cerâmica. As matérias-primas usadas na formulação de massas de porcelanato assumem, em geral, características mineralógicas distintas, na qual cada uma exerce uma função específica. Basicamente, uma massa de porcelanato é composta por uma mistura contendo argilas, feldspatos, areias feldspáticas, carbonatos e caulins [1]. Geralmente, os carbonatos utilizados na produção da massa cerâmica são extraídos de jazidas que contêm minerais como calcário e dolomita (carbonato de cálcio e magnésio).

*liszandra.h@gmail.com
A composição químico-mineralógica destes carbonatos aponta para uma potencialidade de aplicação em massa de cerâmica de revestimento, devido à presença de óxidos fundentes capazes de formar novas fases cristalinas que contribuem para uma melhoria da estabilidade dimensional e resistência mecânica de amostras sinterizadas [2]. Porém, a utilização de carbonatos na massa cerâmica requer cuidados, principalmente no que se refere à granulometria do material particulado e ao ciclo de queima adotado, a fim de evitar o surgimento de defeitos após a etapa de queima [3]. Contudo, o uso dos carbonatos provenientes de fontes minerais vem causando vasta degradação ao meio ambiente, assim como aumentando a escassez destes minerais. Logo, faz-se necessário realizar estudos que possam contribuir não apenas com a diminuição do impacto ambiental, mas 
também economizar as reservas minerais naturais. Nos últimos anos a indústria cerâmica tem usado resíduos em substituição a algumas matérias-primas com o intuito de incentivar a prática de reciclagem e economizar as matériasprimas de melhor qualidade [4]. Ademais, outro grande problema tem obtido destaque devido ao descarte de resíduo de conchas de mariscos no meio ambiente: a pesca de mariscos, no município de Cabedelo (Paraíba, Brasil), é uma das atividades comerciais mais importantes da comunidade pesqueira deste município. O processo de beneficiamento, após a extração do molusco, gera elevada quantidade de conchas, cujo descarte, em volume considerável, provoca assoreamento de áreas extensas e consequente desequilíbrio ambiental. As conchas de moluscos bivalves (mariscos, ostras, mexilhões, etc.) possuem aproximadamente $98 \%$ de carbonato de cálcio $\left(\mathrm{CaCO}_{3}\right.$ - nas formas de calcita e aragonita) [5].

$\mathrm{O}$ carbonato de cálcio $\left[\mathrm{Ca}\left(\mathrm{CO}_{3}\right)\right]$ é um dos carbonatos mais abundantes na crosta terrestre. Ele pode ser encontrado na natureza em três formas cristalinas: calcita (mais estável), aragonita (metaestável) e vaterita, sendo esta última a forma mais rara [6]. Essa substância tem sido comumente utilizada como fundente em vários processos industriais. Em países europeus, como Itália e Espanha, é comum a utilização de argilas carbonatadas, especialmente na fabricação de revestimentos cerâmicos [7]. Durante o processo de queima, os carbonatos decompõem-se formando óxidos de metais alcalinos e alcalinos terrosos que podem reagir com partículas de alumina e sílica livre formando fases cristalinas feldspáticas que formam fase líquida durante o processo de sinterização. Especificamente, o uso do carbonato de cálcio promove a formação da fase cristalina anortita $(\mathrm{CaO}$. $\mathrm{Al}_{2} \mathrm{O}_{3} .2 \mathrm{SiO}_{2}$ ) proveniente da reação entre óxidos de cálcio, silício e alumínio provenientes da constituição química de argilominerais. Primordialmente ocorre a formação da fase cristalina gehlenita $\left(2 \mathrm{CaO} \cdot \mathrm{Al}_{2} \mathrm{O}_{3} \cdot \mathrm{SiO}_{2}\right)$, que pode ser formada a partir da reação entre $\mathrm{CaO}$ e metacaulinita. Com o aumento da temperatura a gehlenita combina-se com sílica e alumina provenientes da decomposição da metacaulinita e/ou com partículas finas de quartzo, originando feldspato cálcico, também conhecido como anortita [8]. O calcário está naturalmente presente em composições de algumas argilas e estudos indicam que a introdução de $5 \%$ de calcário na argila causa redução de sua retração de queima da ordem de $0,5 \%$. Esse comportamento é o mesmo detectado nas massas de cerâmicas monoporosas fabricadas por via úmida, onde o calcário é propositalmente introduzido na forma de calcita para o aumento da estabilidade dimensional do produto [9].

Estudos indicaram que a adição do carbonato de cálcio em massas cerâmicas, desde que devidamente controlada, contribui com a diminuição da temperatura de sinterização e melhora a resistência à compressão, minimizando, de forma indireta, os efeitos da expansão por umidade. É provável que as interações entre os óxidos de cálcio, silício e alumínio, resultantes da decomposição dos argilominerais, contribuam para essas mudanças; no entanto, em quantidades excessivas, a presença do óxido de cálcio pode ser maléfica, uma vez que o processo de hidratação do $\mathrm{CaO}$ seguida por sua expansão pode causar problemas para as peças cerâmicas [7]. Chiari et al. [10] mostraram que o carbonato de cálcio pode ser utilizado na produção de massa para cerâmicas de revestimentos com o objetivo de eliminar ou diminuir a expansão por umidade (EPU). Observaram que até $15 \%$ em massa de carbonato elimina a EPU das peças cerâmicas; todavia, a utilização de teores acima de $20 \%$ pode conduzir ao aumento da EPU. Soares et al. [11] reportaram o benefício da adição de carbonato misto de cálcio e magnésio $\left[\left(\mathrm{CaMg}\left(\mathrm{CO}_{3}\right)_{2}\right.\right.$ - dolomita] na produção de cerâmica para revestimento. Seus resultados mostraram que o uso da dolomita proporcionou mudanças e melhorias significativas na massa de referência (padrão), possibilitando o seu uso em escala industrial, constatando melhorias de resistência mecânica, absorção de água e retração linear de queima (melhor estabilidade dimensional). Em outra pesquisa no âmbito de revestimentos cerâmicos, Soares et al. [3] realizaram um estudo para comprovar a potencialidade do uso de argilas contaminadas com calcário na produção de placas cerâmicas. Os resultados indicaram que o calcário proporcionou a formação de fases cristalinas à base de cálcio e magnésio, melhorando a estabilidade dimensional e enquadrando as placas cerâmicas na classificação de revestimento semiporoso (segundo norma da ABNT, Brasil).

Ainda no setor de material cerâmico, como também na área de bioengenharia, outras fontes alternativas de carbonato de cálcio foram estudadas na produção de material cerâmico e biomaterial cerâmico. Leite et al. [12] demonstraram em suas pesquisas a possibilidade do uso do resíduo de cascas de ovos galináceos (uma promissora fonte de carbonato de cálcio contendo aproximadamente $98 \%$ de $\mathrm{CaCO}_{3}$ ) como matéria-prima alternativa na indústria do setor cerâmico. Todos os resultados demonstraram características apropriadas para o uso como matériaprima alternativa neste setor. Ademais, foi apontado que o reaproveitamento desse resíduo sólido também contribui diretamente com a prevenção contra a poluição ambiental gerada a partir das indústrias alimentícias. Diversas áreas da bioengenharia contêm pesquisas com relatos sobre o uso de fontes alternativas ricas em carbonato de cálcio. As pesquisas relatam o uso de resíduo de cascas de ovos galináceos e de avestruz como fonte de carbonato de cálcio para a produção de biomaterial cerâmico. Biocimentos de fosfato de cálcio foram sintetizados a partir do uso do resíduo com intuito de utilização na área medicinal com a função de constituição óssea na reparação e reconstrução de tecido ósseo nas áreas clínicas de ortodontia e ortopedia [1315]. Devido à importância do papel desempenhado pelos carbonatos na produção de cerâmicos, este trabalho teve como objetivo analisar os efeitos do uso de pó de conchas de mariscos, uma fonte alternativa de carbonato de cálcio, na composição de fase e nas propriedades tecnológicas de corpos cerâmicos. As propriedades foram comparadas àquelas de amostras preparadas com carbonato de cálcio comercial (fase calcita). 


\section{MATERIAIS E MÉTODOS}

Pós de conchas de mariscos do litoral paraibano e $\mathrm{CaCO}_{3}$ comercial (mineradora da região de Parelhas-RN, granulometria \#200) foram incorporados a uma formulação cerâmica (massa padrão) usada por uma indústria local para a produção de porcelanato. Corpos de prova padrão foram produzidos, como referência, sem adição do $\mathrm{CaCO}_{3}$ (comercial ou proveniente do pó de conchas). As conchas de marisco foram moídas via seca, em moinho de discos, para obtenção de um pó fino, posteriormente peneirado para a obtenção de partículas com diâmetro menor ou igual a 74 um (\#200). Após o peneiramento, foram formuladas composições à base de pó de conchas/massa cerâmica e $\mathrm{CaCO}_{3}$ comercial/massa cerâmica, nas quais o pó de conchas e o $\mathrm{CaCO}_{3}$ comercial foram adicionados em proporções de 0,3,5 e 7\% do teor mássico. Visando permitir o processamento da massa, as formulações foram umidificadas com aproximadamente $7 \%( \pm 1 \%)$ de água destilada. O pó umedecido foi granulado para obtenção de partículas com diâmetro menor ou igual a $425 \mu \mathrm{m}$ (\#35) e mantido em repouso durante $24 \mathrm{~h}$ em recipiente fechado para melhor distribuição da água entre as partículas da massa cerâmica. Corpos de prova foram confeccionados, por prensagem uniaxial, com dimensões aproximadas de $60 \times 20 \times 7 \mathrm{~mm}$, sob pressão de $50 \mathrm{MPa}$ em prensa hidráulica. Em seguida foram mantidos em estufa durante $24 \mathrm{~h}$ a $110 \pm 5^{\circ} \mathrm{C}$. As sinterizações foram realizadas em forno elétrico de queima rápida com precisão de $\pm 0,5^{\circ} \mathrm{C}$ (Fortelab, 1300/3), com taxa de aquecimento de $10^{\circ} \mathrm{C} / \mathrm{min}$ e patamar de $15 \mathrm{~min}$, nas temperaturas de 1210 , 1220 e $1230{ }^{\circ} \mathrm{C}$. Ao final do patamar de sinterização, o resfriamento ocorreu de forma natural em forno fechado e desligado até a temperatura ambiente. Após a sinterização, os corpos de prova foram submetidos aos ensaios tecnológicos para determinação das propriedades físico-mecânicas de absorção de água (AA), porosidade aparente (PA), retração linear de queima (RLQ), massa específica aparente (MEA) e tensão de ruptura a flexão em três pontos (TRF) segundo critérios previstos pela norma NBR 13818/1997. A Tabela I contém as formulações estudadas, obtidas pela combinação das proporções mássicas do pó de conchas e do $\mathrm{CaCO}_{3}$ comercial com a massa padrão para porcelanato.

Tabela I - Formulações com pó de conchas, $\mathrm{CaCO}_{3}$ comercial e massa padrão.

[Table I - Formulations with mollusk shell powder, commercial $\mathrm{CaCO}_{3}$ and standard mass.]

\begin{tabular}{cccccccc}
\hline Formulação & 1 & 2 & 3 & 4 & 5 & 6 & 7 \\
\hline Massa cerâmica (\%) & 100 & 97 & 95 & 93 & 97 & 95 & 93 \\
Pó de conchas (\%) & 0 & 3 & 5 & 7 & 0 & 0 & 0 \\
$\mathrm{CaCO}_{3}$ comercial (\%) & 0 & 0 & 0 & 0 & 3 & 5 & 7 \\
\hline
\end{tabular}

\section{RESULTADOS E DISCUSSÃO}

A análise granulométrica foi realizada com o intuito de quantificar as dimensões dos aglomerados de partículas das matérias-primas usadas. A Fig. 1 apresenta os resultados das análises granulométricas do pó de conchas e do $\mathrm{CaCO}_{3}$ comercial. Estes resultados indicaram que o carbonato de cálcio comercial possui uma distribuição de partículas com tamanhos menores que $1 \mu \mathrm{m}$ mais significativa que o pó de conchas. Isto pode estar associado ao processo de obtenção (moagem em diversas etapas) do $\mathrm{CaCO}_{3}$ comercial na indústria. A considerável presença de partículas maiores $(\sim 100 \mu \mathrm{m})$, em ambas as amostras, pode estar associada à presença de partículas de sílica $\left(\mathrm{SiO}_{2}\right)$ de alta dureza $[15$, 16]. A Tabela II apresenta os resultados de fluorescência de raios X para os pós de conchas e calcita comercial. Estes resultados estão expressos na forma de percentual de óxidos dos elementos químicos que compõem as matérias-primas. É possível observar que o pó de conchas e o carbonato comercial têm as mesmas quantidades de $\mathrm{CaO}(\sim 54 \%)$. Em contrapartida, $\mathrm{o} \mathrm{CaCO}_{3}$ comercial apresenta maior percentual de sílica e alumina, provavelmente oriundos da presença de fragmentos de materiais argilosos resultantes das etapas de extração e beneficiamento. Os baixos teores dos óxidos de alumínio e silício encontrados no pó de conchas podem ser atribuídos à falta de seletividade durante o processo de filtração dos moluscos [5]. A Tabela III apresenta os resultados da análise química realizada na massa padrão de porcelanato. A análise química da massa padrão apresentou $62,50 \%$ de sílica e $22,51 \%$ de alumina. O teor apresentado para a sílica está ligado aos materiais argilosos, como caulim e argila ball-clay, apresentando vários silicatos e minerais acessórios, e à presença de sílica livre, matérias-primas usadas para a produção da massa. $\mathrm{O}$ óxido de alumínio geralmente está associado à caulinita, $\mathrm{Al}_{2} \mathrm{Si}_{2} \mathrm{O}_{5}(\mathrm{OH})_{4}$, e aos minerais acessórios. O teor de óxido de potássio apresentado na análise pode ser atribuído aos feldspatos, micas e cátions trocáveis.

A Fig. 2a apresenta o difratograma de raios $\mathrm{X}$ do pó de conchas e do carbonato de cálcio comercial. Para o difratograma do pó de conchas (Fig. 2a, A) podem ser observados picos de difração para duas formas cristalinas
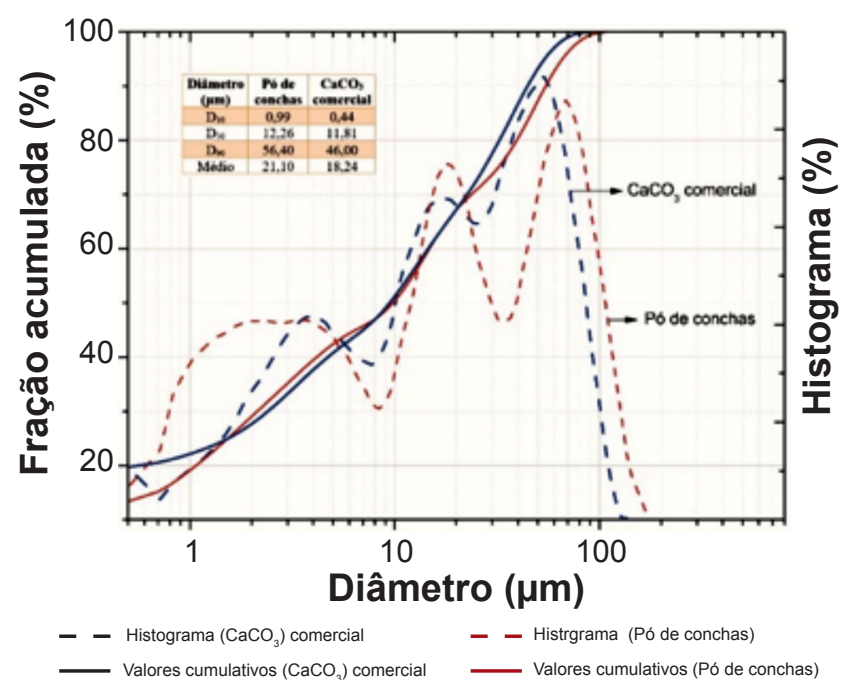

Figura 1: Curvas de distribuição de tamanho de partículas do pó de conchas e do $\mathrm{CaCO}_{3}$ comercial.

[Figure 1: Particle size distribution curves of mollusk shell and commercial $\mathrm{CaCO}_{3}$ powders.] 
Tabela II - Composição química (\% em massa) dos pós de conchas e $\mathrm{CaCO}_{3}$ comercial.

[Table II - Chemical composition (wt\%) of mollusk shell and $\mathrm{CaCO}_{3}$ commercial powders.]

\begin{tabular}{ccc}
\hline Óxido & $\begin{array}{c}\text { Pó de conchas de } \\
\text { mariscos }\end{array}$ & $\begin{array}{c}\mathrm{CaCO}_{3} \\
\text { comercial }\end{array}$ \\
\hline $\mathrm{CaO}$ & 53,8 & 53,7 \\
$\mathrm{SiO}_{2}$ & 0,40 & 2,08 \\
$\mathrm{Al}_{2} \mathrm{O}_{3}$ & 0,16 & 0,71 \\
Outros óxidos & 1,34 & 1,61 \\
Perda ao fogo & 44,3 & 41,9 \\
\hline
\end{tabular}

do $\mathrm{CaCO}_{3}$ : aragonita e calcita. As difrações mais intensas ocorreram nas distâncias interplanares de 3,39 ̊̊ (111), 3,27

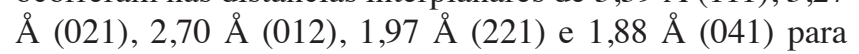
a aragonita em sua estrutura ortorrômbica (grupo espacial Pmcn) e $3,03 \AA$ A (104) e 1,87 ̊̊ (116) para a calcita com estrutura romboédrica (grupo espacial R-3c). Por outro lado, o difratograma do $\mathrm{CaCO}_{3}$ comercial (Fig. 2a, B) apresentou picos de difração apenas da calcita. A Fig. $2 b$ apresenta o difratograma de raios $\mathrm{X}$ da massa padrão de porcelanato. A análise mineralógica identificou picos de difração predominantes do quartzo [4,23 $\mathrm{A}$ (100), 3,33 $\AA$ (101)] em sua estrutura hexagonal, da caulinita [7,10 $\AA$ (001)] e da mica moscovita [9,85 $\mathrm{A}(002), 4,42 \AA(-111), 2,55 \AA$ (131)], corroborando a presença da sílica e alumina evidenciada por fluorescência de raios X. Também foram identificados picos referentes à difração de cristais de feldspato sódico (albita) em $6,35 \AA$ (001), 4,01 $\AA$ (-201) e 3,18 $\AA$ (040).

A retração linear de queima (RLQ) para as diversas formulações em estudo é apresentada na Fig. 3. Independente da fonte de cálcio usada, pó de concha ou calcita comercial, observou-se que com o aumento do teor destes materiais os valores de retração foram maiores nas menores temperaturas de sinterização, variando de $6,14 \%$ a $7,76 \%$ com a adição de pó de conchas e de $6,52 \%$ a $8,14 \%$ com $\mathrm{CaCO}_{3}$ comercial. Os corpos de prova padrão apresentaram RLQ com variação de $6,93 \%$ a $8,82 \%$. Os corpos de prova contendo carbonato de cálcio obtiveram os menores valores médios de retração linear de queima, o que indicou que o carbonato de cálcio desempenha uma função de controlador dimensional, podendo minimizar a ocorrência de trincas na microestrutura cerâmica. Esse comportamento se deve à formação de fases cristalinas de baixa densidade durante o aquecimento das peças em temperaturas superiores a $1000{ }^{\circ} \mathrm{C}$ [9]. Observou-se que as composições com a calcita comercial apresentaram valores de retração linear discretamente superiores em relação às composições com as
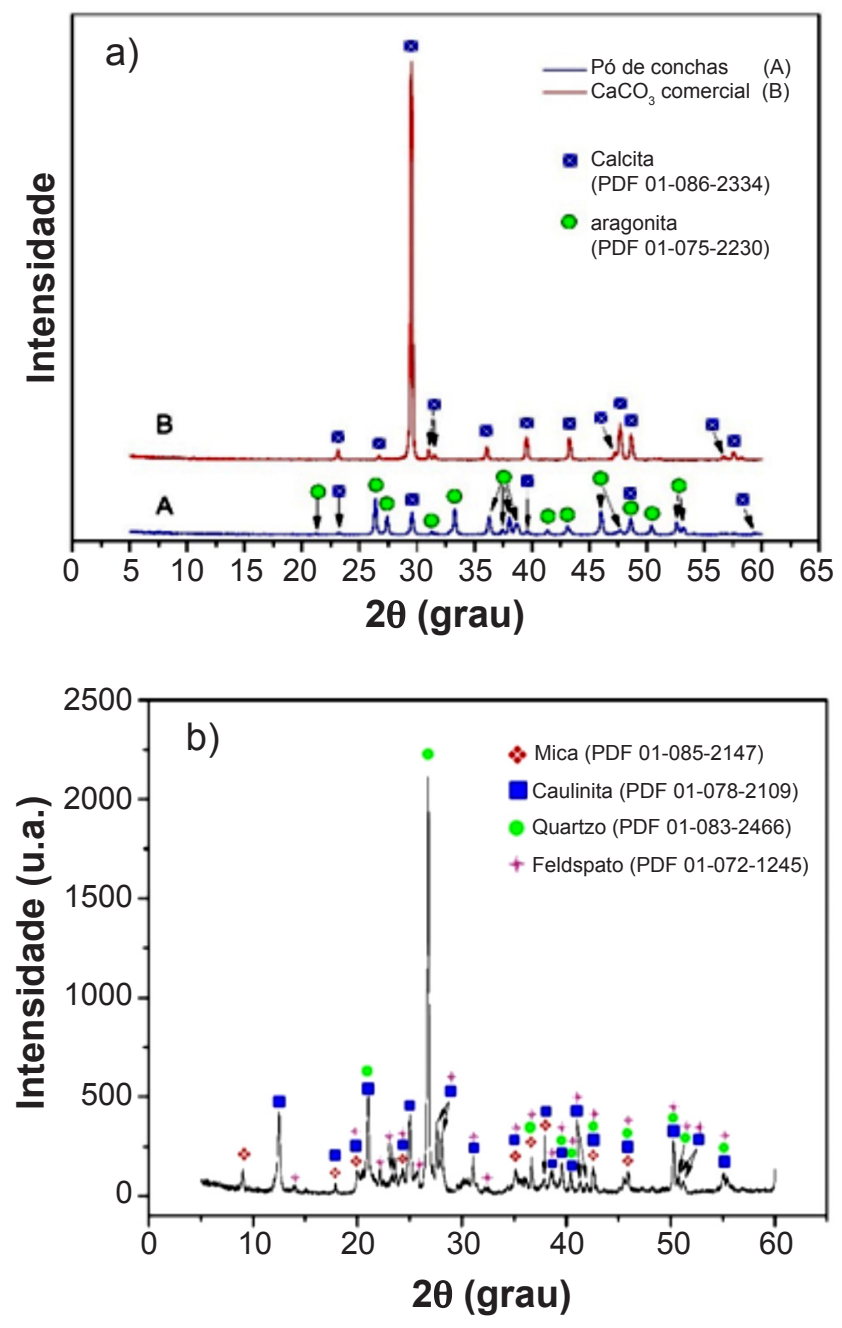

Figura 2: Difratogramas de raios $\mathrm{X}$ de: (a) pó de conchas de marisco e $\mathrm{CaCO}_{3}$ comercial; e (b) massa padrão de porcelanato.

[Figure 2: X-ray diffraction patterns of: (a) mollusk shell and commercial $\mathrm{CaCO}_{3}$ powders; and (b) standard porcelain tile mass.]

conchas, para todas as temperaturas de queima, o que pode ser explicado com base nos resultados da granulometria. As partículas mais grosseiras do pó de conchas participaram das reações químicas com maior dificuldade, devido à sua menor superfície específica livre, o que retarda a formação da fase líquida [17]. A reatividade limitada da formulação cerâmica contendo o pó de conchas resultou em amostras com menores valores de retração linear.

ATabela IV apresenta os valores médios para os resultados dos ensaios de absorção de água (AA), porosidade aparente (PA) e massa específica aparente (MEA). Os menores valores de $\mathrm{PA}$ encontram-se ligados à menor temperatura de sinterização $\left(1210{ }^{\circ} \mathrm{C}\right)$, fato devidamente explicado

Tabela III - Composição química da massa padrão de porcelanato (\% em massa).

[Table III - Chemical composition of the standard mass for porcelain tile (wt\%).]

\begin{tabular}{cccccccc}
\hline $\mathrm{SiO}_{2}$ & $\mathrm{Al}_{2} \mathrm{O}_{3}$ & $\mathrm{~K}_{2} \mathrm{O}$ & $\mathrm{CaO}$ & $\mathrm{MgO}$ & $\mathrm{Na}_{2} \mathrm{O}$ & Outros óxidos & Perda ao fogo \\
\hline 62,5 & 22,51 & 3,05 & 1,34 & 0,97 & 0,96 & 1,18 & 7,49 \\
\hline
\end{tabular}


Teor de massa cerâmica branca (\%)

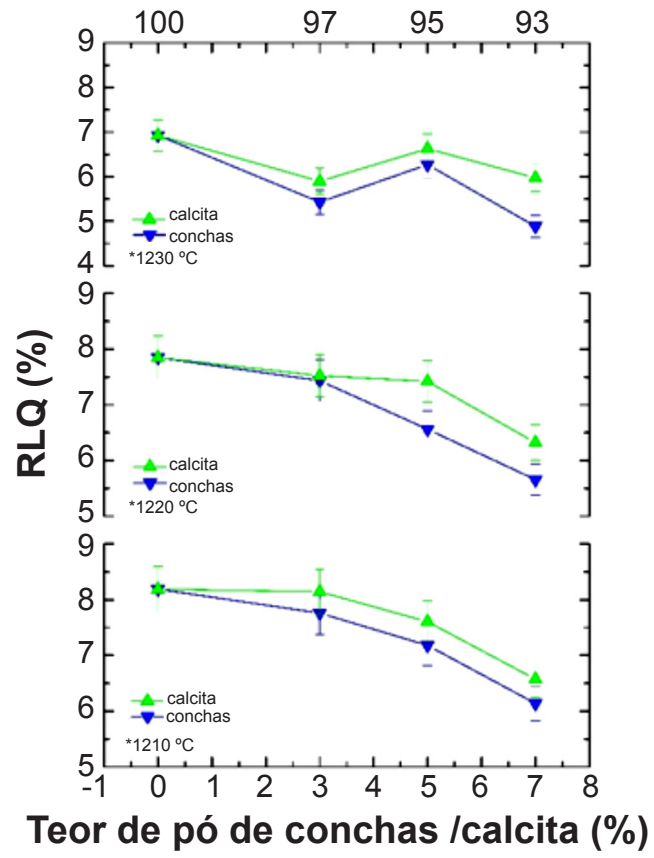

Figura 3: Retração linear após sinterização entre 1210 e $1230{ }^{\circ} \mathrm{C}$. [Figure 3: Linear shrinkage after firing between 1210 and $1230{ }^{\circ} \mathrm{C}$.]

pela menor pressão interna dos gases nos poros, facilitando a densificação por escoamento de fluxo via sinterização por fase líquida [18]. Os resultados da análise de MEA encontram-se intrinsecamente ligados à quantidade de poros abertos. Observou-se que a MEA diminuiu gradualmente com o aumento do teor de $\mathrm{CaCO}_{3}$, entre $3 \mathrm{e} 7 \%$, corroborando o aumento da PA. A partir dos resultados tabelados, observase que os valores da massa específica aparente dos corpos cerâmicos com $\mathrm{CaCO}_{3}$ sinterizados a $1210{ }^{\circ} \mathrm{C}$ encontramse próximos aos valores da massa específica apresentados pelos corpos de prova padrão sinterizados a $1220{ }^{\circ} \mathrm{C}$ e $1230{ }^{\circ} \mathrm{C}$, indicando uma diminuição da temperatura ótima de sinterização. A densificação dos corpos de prova com adição de carbonato de cálcio em temperaturas mais baixas é facilitada pela presença da anortita $\left(\mathrm{CaO} \cdot \mathrm{Al}_{2} \mathrm{O}_{3} \cdot 2 \mathrm{SiO}_{2}\right)$, um mineral do grupo dos feldspatos que forma fase líquida durante a sinterização. A formação da anortita ocorre como resultado da reação entre o óxido de cálcio $(\mathrm{CaO})$ e os óxidos de alumínio e silício provenientes dos argilominerais da massa padrão. Inicialmente há formação de gehlenita $\left(2 \mathrm{CaO} \cdot \mathrm{Al}_{2} \mathrm{O}_{3} \cdot \mathrm{SiO}_{2}\right)$ que se combina com sílica e alumina, provenientes da decomposição da metacaulinita ou com partículas finas de quartzo, para originar a anortita [8].

A Fig. 4 apresenta o comportamento da resistência mecânica sob flexão em três pontos em função do percentual de carbonato de cálcio. Observou-se que os valores médios apresentados para os corpos de prova contendo 3 e $5 \%$

\section{Teor de massa cerâmica branca (\%)}

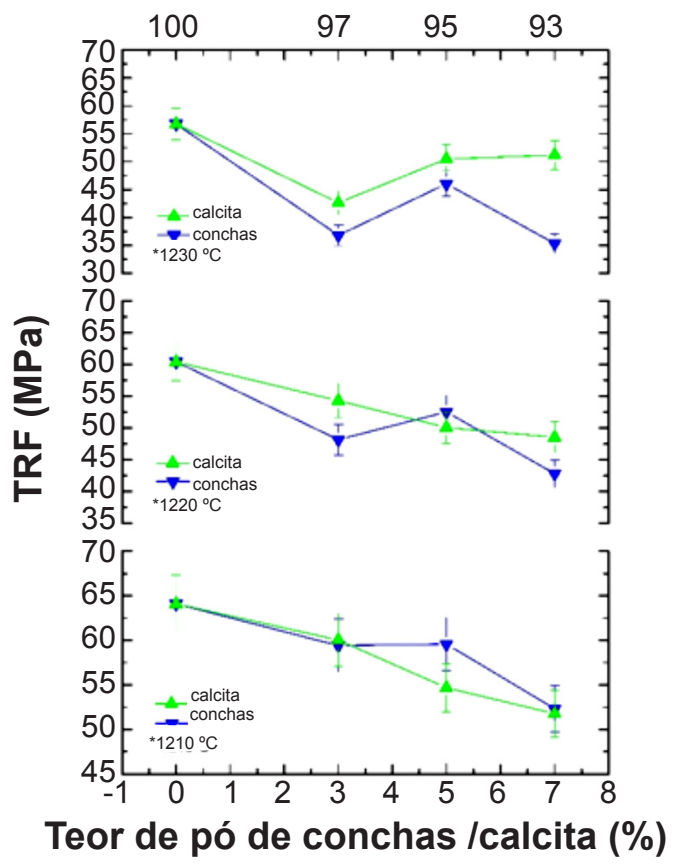

Figura 4: Módulo de ruptura (TRF) dos corpos de prova após sinterização.

[Figure 4: Modulus of rupture (TRF) of sintered samples.]

Tabela IV - Absorção de água (AA), porosidade aparente (PA) e massa específica aparente (MEA) dos corpos de prova após sinterização a 1210,1220 e $1230{ }^{\circ} \mathrm{C}$.

[Table IV - Water absorption (AA), apparent porosity (PA), and apparent specific mass (MEA) of sintered samples at 1210, 1220 and $1230{ }^{\circ} \mathrm{C}$.]

\begin{tabular}{|c|c|c|c|c|c|c|c|c|c|}
\hline \multirow[b]{2}{*}{ Formulação } & \multicolumn{3}{|c|}{$1210^{\circ} \mathrm{C}$} & \multicolumn{3}{|c|}{$1220^{\circ} \mathrm{C}$} & \multicolumn{3}{|c|}{$1230^{\circ} \mathrm{C}$} \\
\hline & $\begin{array}{l}\text { AA } \\
(\%)\end{array}$ & $\begin{array}{l}\mathrm{PA} \\
(\%)\end{array}$ & $\begin{array}{c}\text { MEA } \\
\left(\mathrm{g} / \mathrm{cm}^{3}\right)\end{array}$ & $\begin{array}{l}\mathrm{AA} \\
(\%)\end{array}$ & $\begin{array}{l}\mathrm{PA} \\
(\%)\end{array}$ & $\begin{array}{c}\text { MEA } \\
\left(\mathrm{g} / \mathrm{cm}^{3}\right)\end{array}$ & $\begin{array}{l}\text { AA } \\
(\%)\end{array}$ & $\begin{array}{l}\mathrm{PA} \\
(\%)\end{array}$ & $\begin{array}{c}\text { MEA } \\
\left(\mathrm{g} / \mathrm{cm}^{3}\right)\end{array}$ \\
\hline 1 & $0,03 \pm 0,00$ & $0,06 \pm 0,00$ & $2,39 \pm 0,12$ & $0,02 \pm 0,00$ & $0,04 \pm 0,00$ & $2,35 \pm 0,12$ & $0,02 \pm 0,00$ & $0,04 \pm 0,00$ & $2,28 \pm 0,11$ \\
\hline 2 & $0,04 \pm 0,00$ & $0,10 \pm 0,01$ & $2,33 \pm 0,12$ & $0,08 \pm 0,00$ & $0,17 \pm 0,01$ & $2,27 \pm 0,11$ & $0,05 \pm 0,00$ & $0,11 \pm 0,02$ & $2,17 \pm 0,11$ \\
\hline 3 & $0,04 \pm 0,00$ & $0,08 \pm 0,00$ & $2,28 \pm 0,11$ & $0,06 \pm 0,00$ & $0,14 \pm 0,01$ & $2,26 \pm 0,11$ & $0,06 \pm 0,00$ & $0,14 \pm 0,02$ & $2,23 \pm 0,11$ \\
\hline 4 & $0,40 \pm 0,02$ & $0,89 \pm 0,04$ & $2,21 \pm 0,11$ & $0,36 \pm 0,02$ & $0,78 \pm 0,04$ & $2,16 \pm 0,11$ & $0,36 \pm 0,02$ & $0,77 \pm 0,04$ & $2,09 \pm 0,10$ \\
\hline 5 & $0,07 \pm 0,00$ & $0,17 \pm 0,00$ & $2,34 \pm 0,12$ & $0,05 \pm 0,00$ & $0,12 \pm 0,01$ & $2,31 \pm 0,12$ & $0,07 \pm 0,00$ & $0,13 \pm 0,01$ & $2,19 \pm 0,11$ \\
\hline 6 & $0,07 \pm 0,00$ & $0,16 \pm 0,01$ & $2,28 \pm 0,11$ & $0,07 \pm 0,00$ & $0,16 \pm 0,01$ & $2,27 \pm 0,12$ & $0,04 \pm 0,00$ & $0,09 \pm 0,01$ & $2,24 \pm 0,11$ \\
\hline 7 & $0,14 \pm 0,01$ & $0,28 \pm 0,01$ & $2,20 \pm 0,11$ & $0,08 \pm 0,00$ & $0,17 \pm 0,01$ & $2,23 \pm 0,11$ & $0,07 \pm 0,00$ & $0,15 \pm 0,01$ & $2,20 \pm 0,11$ \\
\hline
\end{tabular}


de carbonato de cálcio, sinterizados a 1210 e $1220{ }^{\circ} \mathrm{C}$, encontraram-se próximos aos valores médios dos corpos de prova padrão sinterizados a 1220 e $1230{ }^{\circ} \mathrm{C}$. Esse comportamento sucede-se devido à presença do carbonato de cálcio, que pode acelerar a cinética de reação entre as partículas, além de originar feldspato cálcico (anortita) que auxilia a densificação em menores temperaturas. Por outro lado, para os corpos de prova com pó de conchas sinterizados a $1230{ }^{\circ} \mathrm{C}$, observou-se um decréscimo na resistência à ruptura, obtendo valor médio próximo ao mínimo de $35 \mathrm{MPa}$ especificado pela ABNT para a classificação como cerâmica de revestimento tipo BIa. Este problema pode ser atribuído a uma maior concentração de defeitos volumétricos, principalmente poros, resultantes da alta pressão de gases [19]. Contudo, nas temperaturas de sinterização de 1210 e $1220^{\circ} \mathrm{C}$, os corpos de prova contendo carbonato de cálcio obtiveram resultados satisfatórios, dentro dos valores exigidos pela norma NBR13818/1997 para revestimentos cerâmicos do tipo BIa. Observou-se que, em geral, houve uma tendência de as composições com a calcita comercial apresentarem valores de tensão de ruptura à flexão superiores aos das composições com o pó de conchas, o que pode ser justificado da mesma forma explicada anteriormente ao avaliar a retração linear de queima, em que as partículas mais grosseiras do pó de conchas apresentaram menor reatividade o que pode contribuir para uma discreta redução da resistência mecânica dos corpos cerâmicos.

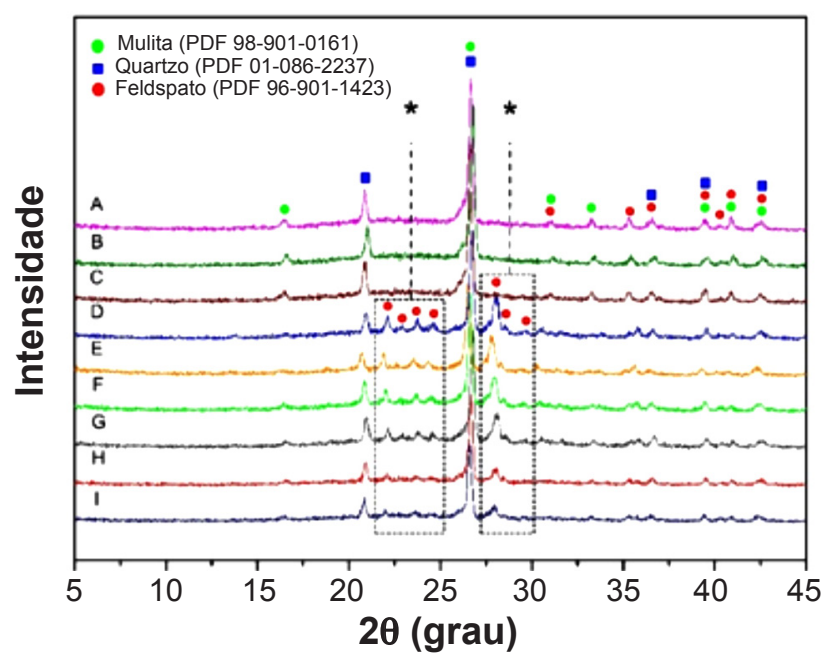

Figura 5: Difratogramas de raios $X$ de amostras selecionadas sinterizadas nas temperaturas indicadas: (A) $100 \%$ massa de porcelanato (MP), $1210{ }^{\circ} \mathrm{C}$; (B) $100 \% \mathrm{MP}, 1220{ }^{\circ} \mathrm{C}$; (C) $100 \%$ $\mathrm{MP}, 1230{ }^{\circ} \mathrm{C}$; (D) $97 \% \mathrm{MP}+3 \%$ pó de conchas, $1210{ }^{\circ} \mathrm{C}$; (E) $95 \%$ $\mathrm{MP}+5 \%$ pó de conchas, $1220{ }^{\circ} \mathrm{C}$; (F) $93 \% \mathrm{MP}+7 \%$ pó de conchas, $1230{ }^{\circ} \mathrm{C}$; (G) $97 \% \mathrm{MP}+3 \%$ calcita, $1210{ }^{\circ} \mathrm{C}$; (E) $95 \% \mathrm{MP}+5 \%$ calcita, $1220^{\circ} \mathrm{C}$; (F) $93 \% \mathrm{MP}+7 \%$ calcita, $1230{ }^{\circ} \mathrm{C}$.

[Figure 5: X-ray diffractograms of selected samples sintered at the indicated temperatures: (A) $100 \%$ porcelain tile mass (PM), 1210 ${ }^{\circ} \mathrm{C}$; (B) $100 \%$ PM, $1220{ }^{\circ} \mathrm{C}$; (C) 100\% PM, $1230{ }^{\circ} \mathrm{C}$; (D) $97 \%$ $P M+3 \%$ mollusk shell powder, $1210{ }^{\circ} \mathrm{C}$; (E) $95 \%$ PM+5\% mollusk shell powder, $1220{ }^{\circ} \mathrm{C} ;(F) 93 \%$ PM+7\% mollusk shell powder, $1230{ }^{\circ} \mathrm{C}$; (G) $97 \% \mathrm{PM}+3 \%$ calcite, $1210{ }^{\circ} \mathrm{C}$; (E) $95 \% \mathrm{PM}+5 \%$ calcite, $1220^{\circ} \mathrm{C}$; (F) $93 \% \mathrm{PM}+7 \%$ calcite, $1230^{\circ} \mathrm{C}$.]
A Fig. 5 apresenta os difratogramas de raios $\mathrm{X}$ de nove amostras selecionadas em diferentes temperaturas de sinterização, sendo uma composição para cada temperatura, uma vez que todos os difratogramas analisados mostraram-se idênticos, apenas variando a intensidade dos picos difratados. De acordo com os difratogramas, verificou-se a presença de picos de difração do feldspato sodo-cálcico, nomeadamente oligoclásio, nos difratogramas classificados como D a I, correspondentes às formulações com adição de pó de conchas de marisco ou carbonato de cálcio comercial. Os picos de difração marcados com asterisco estão associados às distâncias interplanares 4,03, 3,76, 3,18, 2,69, 2,53, 2,50, 2,56 e 2,28 ̊. O mineral oligoclásio $\left[(\mathrm{Na}, \mathrm{Ca}) \mathrm{Al}_{1-2} \mathrm{Si}_{3-2} \mathrm{O}_{8}\right]$ pertence ao grupo plagioclásio feldspato; sua formação é proveniente de reações entre as fases albita e anortita, quando a proporção sodocálcica varia entre 70-90\% de albita e 10-30\% de anortita [20]. Estes resultados corroboraram a formação da fase feldspática anortita que após reagir com albita originou a fase feldspática oligoclásio.

\section{CONCLUSÕES}

Constatou-se que os valores sugeridos pela norma NBR 13818/1997 - Placas cerâmicas para revestimentos: especificações e métodos, foram atendidos nas várias formulações propostas neste trabalho. De maneira geral, a introdução do carbonato de cálcio, em até 7\% em massa, proveniente das conchas de marisco, proporcionou às propriedades mecânicas os valores desejados ao produto final, mantendo a classificação dos corpos cerâmicos como BIa, porcelanato (NBR 13818/1997). Os ensaios tecnológicos mostraram que o $\mathrm{CaCO}_{3}$ desempenha uma função de regulador dimensional, podendo evitar trincas microestruturais e diminuir a temperatura de sinterização. $\mathrm{O}$ carbonato de cálcio proveniente das conchas de mariscos contribuiu com a formação da fase cristalina anortita, que em combinação com a albita originou uma fase feldspática sodo-cálcica (oligoclásio). Como fundente, o oligoclásio promoveu estabilidade dimensional e acelerou a densificação das cerâmicas. Os resultados apresentados pelos ensaios tecnológicos confirmaram a tendência de diminuição da temperatura de sinterização devido à maturação da massa antes da temperatura utilizada para a sinterização da massa padrão, ocasionando redução de custos energéticos e do tempo do ciclo de sinterização. Dessa forma, entende-se que as conchas de mariscos são uma matéria-prima promissora para a indústria cerâmica, contribuindo com a minimização do impacto ambiental causado pelo seu descarte inadequado nas comunidades pesqueiras. As conchas de marisco têm potencial para substituir o carbonato de cálcio comercial, minimizando a degradação ambiental causada pela extração desta matériaprima.

\section{AGRADECIMENTOS}

A CAPES pelo apoio financeiro, a Universidade Federal de Campina Grande (UFCG) pelos resultados de difração de 
raios X e ao Professor Ulisses Targino Bezerra (IFPB - João Pessoa) pelo fornecimento das conchas de mariscos.

\section{REFERÊNCIAS}

[1] A.P. Novaes, Cerâm. Ind. 3, 3 (1998) 34.

[2] R.A.L. Soares, R.M. do Nascimento, C.A. Paskocimas, R.J.S. Castro, Cerâmica 60 (2014) 516.

[3] R.A.L. Soares, R.J.S. Castro, R.M. Nascimento, Cerâmica 58 (2012) 475.

[4] R. Bedi, R. Chandra, S.P. Singh, J. Compos. 2013 (2013) 1.

[5] U.T.A. Bezerra, F.L.P. Almeida, L.B. Silva, N.P. Barbosa, T.A. Passos, D.G.L. Cavalcante, J. Civ. Eng. Archit. 5, 4 (2011) 363.

[6] J.D. Lee, Química inorgânica não tão concisa, $5^{\text {a }}$ Ed., Edgard Blucher, S. Paulo (1999).

[7] J.C.S. Oliveira, B.B. Lira, Y.P. Yadava, C.M.M. Silva, T.W.G. Santos, Cerâm. Ind. 16, 5 (2011) 34.

[8] K. Traoré, T.S. Kabré, P. Blanchart, Ceram. Int. 29 (2003) 377.

[9] F.G. Melchiades, C. Del Roveri, J. Sotéiro, L.L. Silva, A.O. Boschi, Cerâm. Ind. 6, 4 (2001) 27.

[10] L.C. Chiari, C.J. Oliveira, C. Monteiro, N.V. Forjaz, E.
Biscaro, L.F. Marino, A.O. Boschi, Cerâm. Ind. 1 (1996) 35. [11] R.A.L. Soares, R.J.S. Castro, R.M. Nascimento, A.E. Martinelli, Cerâm. Ind. 15 (2010) 2.

[12] F.H.G. Leite, T.F. Almeida, J.N.F. Holanda, Acta Sci. Techn. 3 (2015) 39.

[13] T.H.A. Corrêa, R.S.T. Manhães, J.N.F. Holanda, in: I Enc. Eng. Ciênc. Mater. Inov. Est. Rio Jan., Rio de Janeiro (2015).

[14] J.R.M. Ferreira, L.H.L. Louro, A.M. Costa, J.B. de Campos, M.H. Prado da Silva, Cerâmica 62 (2016) 386.

[15] A.J. Rodolfo, L.R. Nunes, W. Ormanji, Tecnologia do $P V C, 2^{a}$ Ed., Pro Editores, S. Paulo (2006).

[16] G. Pritchard, Plastics additives, an A-Z reference, Chapman Hall, London (1998).

[17] S.R. Bragança, C.P. Bergmann, H. Hubner, J. Eur. Ceram. Soc. 26 (2006) 3761.

[18] F.J.S. Arantes, D.F. Galesi, E. Quinteiro, A.O. Boshi, Cerâm. Ind. 6, 3 (2001) 18.

[19] M.L. Varela, F.L. Formiga, R.P.S. Dutra, R.M. Nascimento, C.A. Paskocimas, Cerâmica 55 (2009) 209.

[20] Dana y Hurlbut, Manual de mineralogía, 17ª Ed., Ed. Reverté, Barcelona (1960).

(Rec. 25/05/2017, Rev. 20/09/2017, 27/12/2017, Ac. 24/01/2018) 